\title{
Environment benefits in UK
}

\section{London}

THE Natural Environmental Research Council (NERC) and the Agricultural and Food Research Council (AFRC) come off best in the shareout of the UK science budget released last week by John MacGregor, Secretary of State for Education and Science. Both receive about 10 per cent more than in 1989-90. MacGregor stressed that the allocations to the five research councils will benefit environmental research.

Funds are set aside for instruments to be carried on the European Space Agency's new remote-sensing satellite (ERS-2), and for NERC to participate in the World Ocean Circulation Experiment, results from which will help scientists model global climate change.

In distributing the total $£ 897$ million (up from $£ 824$ million in 1989-90), the secretary of state stuck, almost to the letter, to advice he received from the Advisory Board for the Research Councils (ABRC). The ABRC advice, published to coincide with MacGregor's announcement, also recommends allocations for the two following years, based on the government's planning figures for science spending. ABRC warns that the government's figures imply "some reduction in the amount of science that can be supported by 1992-93".

NERC's increased share of the budget includes over $£ 17$ million for the British Antartic Survey's new research ship, the James Clark Ross. But nearly half of this is unspent money from 1989-90, carried over into the present budget.

AFRC will spend $£ 12$ million over the next three years continuing the restructuring of its research institutes onto fewer sites. Professor Bill Stewart, Secretary of AFRC, is pleased that the end of restruc-

\begin{tabular}{lc}
\hline \multicolumn{2}{c}{ THE 1990-91 BUDGETS FOR } \\
UK RESEARCH COUNCILS \\
\hline
\end{tabular}

Smaller amounts went to the Royal Society and $A B R C$

turing is now in sight so that, "council will be able to concentrate its funding in future on new science".

With the exception of the Medical Research Council (MRC), which fears that it must withhold funds from highly rated research projects, the councils seem satis- fied with their allocations. AFRC regards the news as "excellent and encouraging", while the Science and Engineering Research Council (SERC) talks of "a reasonable settlement"

Commenting on the varied financial fortunes of the research councils for 199091, science minister Robert Jackson said that a true picture emerged only if funding was considered over a number of years. A ten-year survey showed that the proportion of funds received by each council varied very little, compared with support for different subject areas within each council. This indicated strong management within councils, but too little coordination between them. It is these considerations that prompted ABRC's Morris report to recommend amalgamation of the councils, said Jackson. A decision on the recommendations is expected "very soon". Peter Aldhous

\section{Dual-support system to go?}

\section{London}

MAJOR changes in the way UK scientific research is supported in the universities are recommended in a consultative paper from the Department of Education and Science. The aim is to shift responsibility for funding the overheads of research from the universities to the research councils.

Under the present 'dual support' system, the research councils provide about $£ 250$ million a year to pay for additional costs associated with projects they sponsor, but the universities, through their block grant from the Universities Funding Counci (UFC), pay for existing staff and facilities. The problem is that this distinction has become increasingly blurred, with considerable argument over the balance of funding for some projects.

\section{Japanese papers top the charts}

\section{Washington}

JAPAN may complain about the low standard of its basic research but journal citation figures tell a different story. For the second half of 1989, Japanese groups take two out of the top three positions in the lists of most cited papers in both biology and physics - the first time that this has happened.

The figures come in a new monthly journal called ScienceWatch published by the Institute for Scientific Information, the publishers of Current Contents. In positions two and three on the biology list are papers on endothelin from T. Masaki et al. of the University of Tokyo and on protein kinase $\mathrm{C}$ from Y. Nishizuka of Kobe Medical School. An earlier paper by Nishizuka broke records by becoming the most cited paper of the 1980s. This paper and the two others were all published in Nature.

At the top of the physics list is a paper by T. Asano et al. of the National Research Institute of Metals on a high-temperature superconductor, published in the Japanese Journal of Applied Physics. In the number three position comes S. Uchida et al.'s paper, from the University of Tokyo, on a superconducting copper oxide compound, again published in Nature.

But while Japan can now rightly claim some pinnacles of excellence, the United States still owns most of the high ground.

All the remaining 16 papers in the two top ten lists come from US laboratories.

Alun Anderson
If the government's scheme is introduced, from 1991-92 some $£ 70$ million per year will be transferred from the UFC grant to the research councils' budgets. Applications for research grants must give accurate costings for overheads, such as equipment maintenance and computing costs, to be funded by the research councils. A standard percentage will be added for other, less identifiable expenses, such as telephone charges and library costs.

But there are fears that research supported by charities, which support more medical research in the universities than do the research councils, could suffer under the new arrangements.

Research supported by charity currently benefits from the UFC block grant in much the same way as research council projects.

Although the consultation paper notes that the government does not wish to see any reduction in indirect support for the charities' projects, the Association of Medical Research Charities is worried that there is no explicit mention of a mechanism to maintain the payment of overheads from UFC money.

If universities started to impose charges on the charities for overheads, this "would result in a reduction in the quantity of funded research".

The heads of UK universities are also considering the new system. A spokesman for the Committee of Vice-Chancellors and Principals said that an initial concern was the continued existence of UFC funds to sponsor research from promising new scientists, without the proven 'track record' to attract research council money. The committee is anxious that this facility should continue, despite the reduction in the UFC grant.

Peter Aldhous 